\title{
Most Common Health Care Associated Infections
}

\author{
Aljaifi Saddam Hussein Mohammed', Sadik Yusuf Musse ${ }^{2 *}$ \\ ${ }^{1}$ School of Health Sciences, Wuhan University, Wuhan, China \\ ${ }^{2}$ School of Medicine, Wuhan University, Wuhan, China \\ Email: saddamhussen2010@hotmail.com, ^2011326660013@whu.edu.cn
}

How to cite this paper: Mohammed, A.S.H. and Musse, S.Y. (2020) Most Common Health Care Associated Infections. Open Access Library Journal, 7: e6222.

https://doi.org/10.4236/oalib.1106222

Received: March 12, 2020

Accepted: May 6, 2020

Published: May 9, 2020

Copyright (C) 2020 by author(s) and Open Access Library Inc.

This work is licensed under the Creative Commons Attribution International License (CC BY 4.0).

http://creativecommons.org/licenses/by/4.0/

\begin{abstract}
Background: The acceptable challenges at ongoing comorbidities burdens at the good quality of basics stratify the rate of given 6 tops surveys of common infections in Health associated infections (HAIs) adjusting the population-based study disabling the modeling of confirmed HAIs risk factors. Method and Findings: The additional pneumonia-related health care factors including surgical infection site, Clostridium difficile, neonatal-sepsis, catheter-associated UTI and bloodstream are observed in relation to Health associated infections (HAIs) burden systematically converting the estimation between age group, gender and applied formula of Sudderth and Rhame in life-expectancy of the scoring data population. The Economic Union of 6 cumulative studies with the proportion of 100,000 represents $60 \%$ highest associated subtotal. The actual limitation lies in the parameter of disease modeling, fatal cases, and conceptual framework of the number of incidences proportional to the significance of prevalence modifications. Conclusion: The conducted Health associated infections (HAIs) study trial in 2015-2019 based on the transparent allowance of evidence-based approval targeting the ranking in ascending order at suitable prioritization between most affected and least affected subgroup relative to control group potentially equalizes the site of infection causes that may remain beneficial at some extend in newer cases. Author Summary: The health-associated infections (HAIs) care disability in the yearly based life adjustment measure cases reference to statistics conveniently analyzes the contributable face underlying causative factors initializing the hospital-related complications. Research Findings: The 6 chosen pneumonia-related health infection risk factors, extract the modified data from European sources to conclude the final consumption of anti-microbial effects with acute hospitalized causes. Furthermore, corresponding to $>1.5$ million cases in the Economic estimated European region it remained target surveillance similarly to TB suspected survey. Interpretation: Very few strat-
\end{abstract}


egies of declined risk ratio in epidemiology at developed medical devices in MRSA, were analyzed at a wider range of micro-organism resistance to handle with imperative efforts in taking preventive measures to reduce the risk of etiology related death.

\section{Subject Areas}

Public Health

\section{Keywords}

Surgical Infection Site, Clostridium difficile, Neonatal-Sepsis, Catheter Associated Urinary Tract Infection, Bloodstream

\section{Introduction}

The health-care-associated infections (HAIs) are rapidly becoming a common topic to discuss the higher rate of mortality in the statistic that proportionally remains significant in the morbidity trial to be considered as a preventable case to some extent in the quality measure of affected subunits [1]. Mainly the supporting conducted trials attempted in many cases attribute towards the infected condition elaborating the modeling method for designing the combined study in descriptive characteristic [2] [3] [4] [5] [6].

Whereas, the well-known burden in terms of established technique to tackle the disease account incidence and prevalence prior to disabilities for the risk factors ongoing for many years results in composite factors adjusting the disabilities of DALY analyses [7]. However, the applied over-all HAIs compare both affected and non-affected groups targeting the infection complication specifically in the beneficial role of public and professional policy. The main challenges in the attitude of HAIs in hospitalized condition subjective to comorbidities in the intervention of underlying etiology calculate the expectancy of individuals each year in total by the age group and sources of the death rate. The re-hospitalized cases programmed with discharge from the hospital commonly reflect the precise data accuracy to necessarily make the identification of searched data [8].

On studying the essential background information from collected data it explores the strategies for practices in the improvement and prevention associated with the total number of calculated risk factors. Therefore, surveillance as a powerful object for achieving our aims by following the reference systematically analyzes the essential interpretation plan for public health to manage its impact [9].

\section{Methods}

(Study design on population and sources of data)

The agency of participated candidates in public health (PHAC) includes the committee of epidemiology associated with studies of the nosocomial infectious 
surveillance program and micro-biology linked conditions provide the appendix of study between (2015-2019). However, the included study group from 2009-2017 help to survey the 6 known HAIs including urinary tract infection, bloodstream infection, Clostridium difficile, surgical site infection and acquired pneumonia. Therefore, the absolute compare prevalence with unknown HAIs remains communicable to diagnose the error in the study.

Thus, we analyzed all age groups independently that remain eligible for inclusive study with at least $<48 \mathrm{hrs}$ suffering diseases to evaluate the long-term targeted-effectiveness in terms of unknown risk factors i.e. neo-natal studies, maternity, rehabilitation and sepsis in the unmanageable unit.

The main approach of the study is to timely frame the future research in observing the certain consequences that may lead to premature death cause expressed with control and uncontrolled group with the expected output of the exceptional result.

The availability of primarily selective study based on previous literature reviews, questionnaires, case reports and final surveillance reports we assume the split recognition of health significance relative to targeted syndrome cases that may indirectly be convenient to combine the result with all 6 groups of known HAIs [10] [11].

On the other hand, prevention therapy in controlled group relevant to safety measure defines the standard goal of National Health Care precautions that may exceptionally remain symptomatic on receiving treatment therapy.

\section{Data Collection}

The guidelines in epidemiology helped us to obtain the data from previous references allocating the ongoing research limitation that variate the influences supportive to the years 2015-2019. Firstly, the following demographic values we measured certainly the population per 100,000 incidences based on DALY study calculating widely the adverse events in a number of dysfunction cases seen in Table 1 and Table 2.

Secondly, on countering the prospective studies in normalized HAIs conditions we calculate the preliminary situation from 2 years (2017 and 2018) to carry

Table 1. Ranking of top 6 HA related infections accordingly of 100,000 median populations in 2015.

\begin{tabular}{ccc}
\hline Healthcare-associated Infection & $\begin{array}{c}\text { DALY per } \\
\mathbf{1 0 0 , 0 0 0}\end{array}$ & $\begin{array}{c}\text { Incidence per } \\
\mathbf{1 0 0 , 0 0 0}\end{array}$ \\
\hline HA primary blood stream Infection & 148 & 33.0 \\
Surgical site Infection & 59.1 & 159 \\
Catheter-Urinary tract Infection & 81.5 & 153 \\
Ventilator associated Pneumonia & 173 & 139 \\
HA Clostridium difficile Infection & 32.4 & 32.0 \\
HA Neonatal sepsis & 17.0 & 2.95 \\
\hline
\end{tabular}


out the subtotal percentage in terms of altered from baselines as seen in Table 3.

Thirdly, on proceeding with yearly based estimation in overall 6 actively groups of illness we exhibit the changes in measuring the initially conducted 2017 as more valuable year compared with 2018 that may equally differ the result. However, on keeping 2015 year as a baseline starting point of analysis we try to achieve our aim to profound 2019 accuracy on expecting 20\% reduction as a preventable measure in overall statistics as mentioned in Table 4.

\section{Result}

The declined prevalence in HAIs calculated 2017 we compare the previous trial

Table 2. Data taken to calculate the total number of HACs depended to measure the complications accuracy in 2016.

\begin{tabular}{cc}
\hline Health care-associated Infection & Number of cases in adverse events \\
\hline Iatrogenic respiratory failure & 35,998 \\
Surgical site Infection & 80,200 \\
Others & 32,398 \\
\hline
\end{tabular}

Table 3. Data taken to calculate approximate percentage changes that differentiate the result in comparing 2 years together 2017-2018.

\begin{tabular}{cccc}
\hline $\begin{array}{c}\text { Hospital-acquired } \\
\text { condition }\end{array}$ & $\begin{array}{c}\text { Preliminary 2017 } \\
\text { Normalized count } \\
\text { of HAIs }\end{array}$ & $\begin{array}{c}\text { Preliminary 2018 } \\
\text { Normalized count } \\
\text { of HAIs }\end{array}$ & $\begin{array}{c}\text { Percentage of } \\
\text { HAIs 2017-2018 }\end{array}$ \\
\hline $\begin{array}{c}\text { Catheter-associated Urinary tract } \\
\text { infection }\end{array}$ & 162,000 & -8000 & $-4 \%$ \\
$\begin{array}{c}\text { Central line-associated Bloodstream } \\
\text { infection }\end{array}$ & 7000 & -500 & $-5 \%$ \\
$\begin{array}{c}\text { Clostridium difficile infection } \\
\text { Surgical site infection }\end{array}$ & 55,000 & $-31,000$ & $-36 \%$ \\
Ventilator-associated pneumonia & 72,000 & 0 & 0 \\
Others & 32,000 & -5000 & $-14 \%$ \\
Total & 520,000 & $-75,000$ & $-12 \%$ \\
\hline
\end{tabular}

Table 4. Preliminary data taken at the rate of 2017-2019 comparison exhibiting baseline.

\begin{tabular}{cccc}
\hline $\begin{array}{c}\text { Hospital-acquired } \\
\text { Condition }\end{array}$ & $\begin{array}{c}\text { Baseline } \\
\mathbf{2 0 1 5}\end{array}$ & $\begin{array}{c}\text { Preliminary } \\
\mathbf{2 0 1 7}\end{array}$ & $\begin{array}{c}\text { Gradual reduced } \\
\text { 20\% 2019 Goal }\end{array}$ \\
\hline Catheter-associated Urinary tract infection & 5.9 & 5.5 & 4.5 \\
Central-line associated Bloodstream infection & 0.31 & 0.29 & 0.24 \\
Clostridium difficile infection & 3.0 & 1.8 & 2.3 \\
Surgical site infection & 2.7 & 2.1 & 2.2 \\
Acquired pneumonia & 1.4 & 1.0 & 1.0 \\
Other HAIs & 19.8 & 17.7 & 15.8 \\
Total & 98.4 & 85.6 & 78.0 \\
\hline
\end{tabular}


group that may mostly emphasize on strategies of curable with least of $20 \%$ $30 \%$ in expectancy of recent measured result. Moreover, the composite of 5 years prolonging the life expectancy risk ratio in the premature death ratio derives the nearly equal result in 2017 and 2018 which seek the less approximate chances to projectile the current analysis for global standard outlook measure in both males and females lowest point of observation [12].

Hence, the substantial burden affects a maximum of nearly 1.6 million populations overall 99,000 in the US that may statistically measure the bacterial infection cases highlighting the surgical prosthetic cases emerging highly the concerns of Staphylococcus aureus (MRSA) extending the spectrum of novel research widely to compare past years of 2015 and 2017 references [1] [2] [3] [13] (another article).

\section{Statistical analysis}

The extracted hospital-based data we used SAS software version 9.2 and SPSS software to characterize the profiles of median standard and relative differences $\mathrm{X} 2$ test categorizing $\mathrm{P}$-value 0.05 significance as a continuum variable. Furthermore, each number of calculated cases measure the percentage of least variance in a regressed infectious group exposed yearly survey to differentiate the equation of error generalized for robust estimation as seen in Figure 1.

\section{Computational uncertainty}

The included uncertainties bring the outcome from the actual finalized design

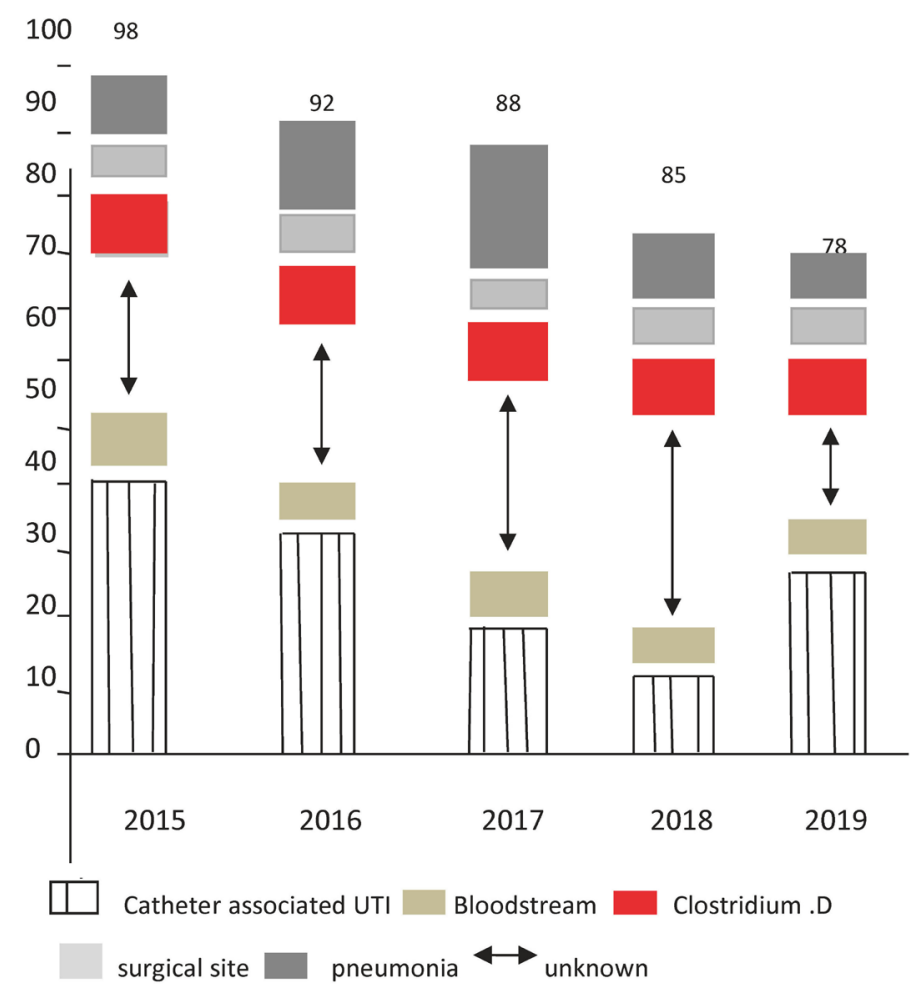

Figure 1. Annually estimated per 100,000 populations are associated with 6 known HAIs median 95\% uncertainty error splitting unknown HAI applying the discounted error and standard error. 
of HAIs customizing the population generation in each subtype targeted group to successfully score the risk factor category incorporating the 2 applicable input variables simulating the interval [12]-[17].

Annually the inclusive criteria of 100,000 cases every year median to $98 \%$ US uncertainty on the timely limit of only $4 \%$ allow the integrity of prevention in HAIs mentioned in Figure 2.

\section{Study population and Incidence}

The specified new cases per 100 individuals use EURO state analysis of 2015 collection to calculate incidence rate with a formula of I = 9XLA (LN-INI) selectively to evaluate 2,719,635 hospitalized and 13,000 discharged annual cases moving towards inpatient 100,000 inhabitants [16] [17].

\section{Ethics statement}

The epidemic-based information in studying of public health subjected in 2019 and published in 2020 regarding infectious diseases require specific consent letter from included participants to aggregate the subjective reports enclosing the age, gender, suffered illness to interpret without any personal interest.

\section{Discussion}

In the consultation of transitional appraisal, it demonstrates the interfering result assuming the subgroup literary the review progression of result defining the published work under the critically attempted surgical risk factors causative of bacteremia [9] [18] [19]. The proposed Rhame of sudden death descriptive of

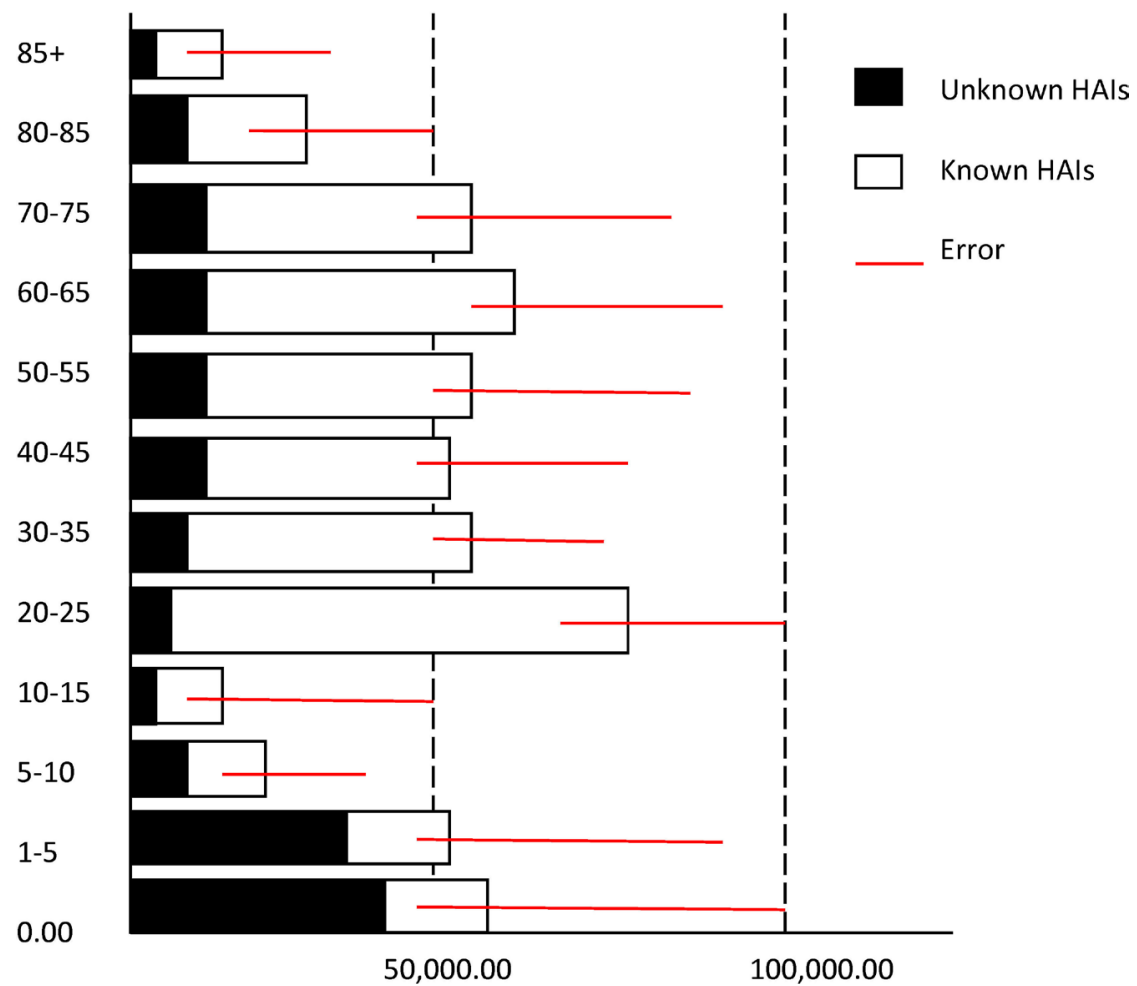

Figure 2. The providing detailed information elaborates the database analysis yearly starting from baseline till preliminary 2019 data to carry out risk factors. 
its specific methodology analyzes the comparison result between inpatient and outpatient cases. The majority of cases from the psychiatric and rehabilitation department are seen with hospitalized complicated cases diversifying the proportion of fatal symptom signifying the cause of sepsis equal to 0.05 respectively.

In general, the exceptional reports of male individuals predominate the neonatal cases with variables of $>65$ age group vulnerable to the population of reoccurrences burden. The setting in presenting study, facilitate the underestimated topics at HAIs by epidemiological means of shorter and longer terms of assessing at greater life expectancy. Despite the relative risk in an advanced way of the communicable period between (2009-2014) it moderately focuses on the targets of influenza and TB. The cautious way of identifying and pointing the micro-organism pathway at the syndromic conditions substantially associate with non-communicable methods equal to controlled cases.

Traditionally on triggering pneumonia like a primary disorder of $60 \%$ in total approaches, it measures the severity utmost to $30 \%$ of its under regressed cumulative study indicating the achievable goals. However, the newborn approximate of $>2590$ cases it assured 12 times congenital and hereditary causes suffering from contagious diseases i.e. Rubella, gonorrhea, and chlamydia. The issue of long-term disadvantage is lacking the significance of evidence perspective to cardiological conditions over $>500$ cases daily with $>400$ respiratory cases, $>11.5$ neonatal sepsis cases and $>40$ diarrhea cases. The sequelae of projecting prevalence of founded septic basic concepts begin early in 2013 for a treatment study plan. Therefore, the increasing trend of fractional microbial anti-resistant klebsiella, pneumonia and acinetobacter is presented in its reduced form at ineffective and in-appropriate terms of attributing responsibility at multi-drug resistant use [20] [21]. Thus, we substantially emphasize the resumed efforts of the controlled groups ultimately in the treated group at preventable safety measures.

\section{Limitations}

The mainly tertiary inpatient collected data at an overall population estimate the robust health care-related sepsis etiology at differently included prevalence type disaggregating the confidential individual. The slighter survey in rational safeguard networking reduces the follow-up to change the sensitivity of result in adopting the lab samples of $C$. difficile from previous studies. Nevertheless, the turnover flowchart in medical sciences at the variated protocols inconsistently attempting to considerate the standard trained concept preceding on collecting the maternity information excluding the briefly suspected results in neonates to make an independent decision for further studies in 2020. Apart from maintaining the balance based on the previous results in 2017 verifying the top trending survey, it must review repeatedly the prevalence-incidence adjustments in the 6 carried out modeling studies at health care specified diseases. 


\section{Conclusion}

According to the fraction of highly mentioned microbial anti-resistance, we expect the inter-country variations likely in phasic changes at inappropriate leading morbidity in HAIs mortality interference. And according to the sequential points from 2015 to 2019, it requires reduction of the uncommon infectious preventable control, majorly through the efforts from European groups of safer surveys permitting the comparative analysis of the recent data.

\section{Conflicts of Interest}

The authors declare no conflicts of interest regarding the publication of this paper.

\section{References}

[1] Umscheid, C.A., Mitchell, M.D., Doshi, J.A., Agarwal, R., Williams, K. and Brennan, P.J. (2011) Estimating the Proportion of Healthcare-Associated Infections That Are Reasonably Preventable and the Related Mortality and Costs. Infection Control \& Hospital Epidemiology, 32, 101-114. https://doi.org/10.1086/657912

[2] World Health Organization (WHO) (2011) Report on the Burden of Endemic Health Care-Associated Infection Worldwide. Geneva. http://apps.who.int/iris/bitstream/10665/80135/1/9789241501507_eng.pdf

[3] Magill, S.S., Edwards, J.R., Bamberg, W., Beldavs, Z.G., Dumyati, G., Kainer, M.A., et al. (2014) Multistate Point-Prevalence Survey of Health Care-Associated Infections. The New England Journal of Medicine, 370, 1198-1208. https://doi.org/10.1056/NEJMoa1306801

[4] Zarb, P., Coignard, B., Griskeviciene, J., Muller, A., Vankerckhoven, V., Weist, K., et al. (2012) The European Centre for Disease Prevention and Control (ECDC) Pilot Point Prevalence Survey of Healthcare-Associated Infections and Antimicrobial Use. Eurosurveillance, 17, pii: 20316. https://doi.org/10.2807/ese.17.46.20316-en http://www.eurosurveillance.org/ViewArticle.aspx?ArticleId=20316

[5] European Centre for Disease Prevention and Control (2009) Annual Epidemiological Report on Communicable Diseases in Europe 2008. ECDC, Stockholm.

[6] European Centre for Disease Prevention and Control (2013) Point Prevalence Survey of Healthcare-Associated Infections and Antimicrobial Use in European Acute Care Hospitals. ECDC, Stockholm.

http://ecdc.europa.eu/en/publications/Publications/healthcare-associated-infections -antimicrobialuse-PPS.pdf

[7] Sherman, E.R., Heydon, K.H., St John, K.H., Teszner, E., Rettig, S.L., Alexander, S.K., et al. (2006) Administrative Data Fail to Accurately Identify Cases of Healthcare-Associated Infection. Infection Control \& Hospital Epidemiology, 27, 332-337. https://doi.org/10.1086/502684

[8] Kretzschmar, M., Mangen, M.J., Pinheiro, P., Jahn, B., Fevre, E.M., Longhi, S., et al. (2012) New Methodology for Estimating the Burden of Infectious Diseases in Europe. PLOS Medicine, 9, e1001205. https://doi.org/10.1371/journal.pmed.1001205

[9] European Centre for Disease Prevention and Control (2012) Point Prevalence Survey of Healthcare-Associated Infections and Antimicrobial Use in European Acute Care Hospitals Protocol Version 4.3. ECDC, Stockholm.

[10] Murray, C.J., Ezzati, M., Flaxman, A.D., Lim, S., Lozano, R., Michaud, C., et al. 
(2012) GBD 2010: Design, Definitions, and Metrics. The Lancet, 380, 2063-2066. https://doi.org/10.1016/S0140-6736(12)61899-6

[11] Mataseje, L.F., Abdesselam, K., Vachon, J., et al. (2016) Results from the Canadian Nosocomial Infection Surveillance Program on Carbapenemase-Producing Enterobacteriaceae, 2010 to 2014. Antimicrobial Agents and Chemotherapy, 60, 6787-6794. https://doi.org/10.1128/AAC.01359-16

[12] Rutledge-Taylor, K., Matlow, A., Gravel, D., et al. (2012) Canadian Nosocomial Infection Surveillance Program. A Point Prevalence Survey of Health Care-Associated Infections in Canadian Pediatric Inpatients. The American Journal of Infection Control, 40, 491-496. https://doi.org/10.1016/j.ajic.2011.08.008

[13] Horan, T.C., Andrus, M. and Dudeck, M.A. (2008) CDC/NHSN Surveillance Definition of Health Care-Associated Infection and Criteria for Specific Types of Infections in the Acute Care Setting. The American Journal of Infection Control, 36, 309. https://doi.org/10.1016/j.ajic.2008.03.002

[14] Taylor, G., Gravel, D., Matlow, A., et al. (2016) Canadian Nosocomial Infection Surveillance Program. Assessing the Magnitude and Trends in Hospital Acquired Infections in Canadian Hospitals through Sequential Point Prevalence Surveys. Antimicrobial Resistance and Infection Control, 5, 19.

https://doi.org/10.1186/s13756-016-0118-3

[15] Simor, A., Pelude, L., Golding, G., et al. (2016) Canadian Nosocomial Infection Surveillance Program. Determinants of Outcome in Hospitalized Patients with Methicillin Resistant Staphylococcus aureus Bloodstream Infection: Results from National Surveillance in Canada 2008-2012. Infection Control \& Hospital Epidemiology, 37, 390-397. https://doi.org/10.1017/ice.2015.323

[16] Gonzales, M., Rocher, I., Fortin, E., et al. (2013) A Survey of Preventive Measures Used and Their Impact on Central Line-Associated Bloodstream Infections (CLABSI) in Intensive Care Units (SPIN-BACC). BMC Infectious Diseases, 13, 562. https://doi.org/10.1186/1471-2334-13-562

[17] AHS (2019) Report on Performance Q2 2018-19: Hand Hygiene Compliance. Alberta Health Services, Edmonton.

[18] Clec'h, C., Schwebel, C., Francais, A., Toledano, D., Fosse, J.P., Garrouste-Orgeas, M., et al. (2007) Does Catheter Associated Urinary Tract Infection Increase Mortality in Critically Ill Patients? Infection Control \& Hospital Epidemiology, 28, 1367-1373. https://doi.org/10.1086/523279

[19] Laupland, K.B., Zygun, D.A., Davies, H.D., Church, D.L., Louie, T.J. and Doig, C.J. (2002) Incidence and Risk Factors for Acquiring Nosocomial Urinary Tract Infection in the Critically Ill. Journal of Critical Care, 17, 50-57.

https://doi.org/10.1053/jcrc.2002.33029

[20] Astagneau, P., Rioux, C., Golliot, F., Brucker, G. and Group INS (2001) Morbidity and Mortality Associated with Surgical Site Infections: Results from the 1997-1999 INCISO Surveillance. Journal of Hospital Infection, 48, 267-274. https://doi.org/10.1053/jhin.2001.1003

[21] Suetens, C., Latour, K., Karki, T., et al. (2018) Prevalence of Health Care-Associated Infections, Estimated Incidence and Composite Antimicrobial Resistance Index in Acute Care Hospitals and Long-Term Care Facilities: Results from Two European Point Prevalence Surveys, 2016 to 2017. Published Erratum in Euro Surveill, 23, pii: 181122e1. Eurosurveillance, 23.

https://doi.org/10.2807/1560-7917.ES.2018.23.46.1800516 